\title{
Assessment of the relation between religiosity, anxiety, depression and psychological resilience in nursing staff
}

\author{
Evangelos C. Fradelos, ${ }^{1}$ Victoria Alikari, ${ }^{2}$ Viktor Vus, ${ }^{3}$ loanna V. Papathanasiou, ${ }^{4}$ \\ Konstantinos Tsaras, ${ }^{4}$ Foteini Tzavella, ${ }^{5}$ Dimitra Lekka ${ }^{1}$ \\ ${ }^{1}$ Psychiatric Department, General Hospital of Athens "Sotiria", Athens, Greece; ${ }^{2}$ Department of \\ Nursing, University of West Attica, Athens, Greece; ${ }^{3}$ International Relations office, Institute for \\ Social and Political Psychology National Academy of Educational Science of Ukraine, Kiev, \\ Ukraine; ${ }^{4}$ Department of Nursing, University of Thessaly, Larisa, Greece; ${ }^{5}$ Department of Nursing, \\ University of Peloponnese, Sparta, Greece
}

\begin{abstract}
The nursing profession is considered to be an emotionally demanding profession often lead to various psychological difficulties and extend level stress. Religiosity and religion in general, have been associated with positive outcomes in an
\end{abstract}

\begin{abstract}
Correspondence: Evangelos C. Fradelos, Psychiatric Department, General Hospital of Athens "Sotiria", Evdoxou 12, Athens PC 11743 Greece.

Tel: +306946228458

E-mail: evagelosfradelos@hotmail.com

Key words: Religiosity, Nursing, Anxiety, Depression, Resilience.

Acknowledgments: The authors would like to thank all nurses that participated in this study.

Contributions: EF: conceived study, wrote the paper; VA: review the literature, wrote the paper; VV: undertook interviews, review the literature, wrote the paper; IVP undertook interviews, review the literature; KT: undertook interviews, review the literature; FT: participated in design and coordination; DL: participated in design and coordination; all authors read and approved the final manuscript, agreed to be accountable for all aspects of the work in ensuring that questions related to the accuracy or integrity of any part of the work are appropriately investigated and resolved.
\end{abstract}

Conflict of interest: The authors declare no conflict of interest.

Funding: None

Availability of data and materials: All study data are available within the text.

Ethics approval and consent to participate: The participants were informed of their rights to refuse or to discontinue their participation, according to the ethical standards of the Helsinki Declaration of 1983. The study was approved by the Medical Research Ethics Committee of each hospital.

Informed consent: Informed consent was obtained.

Received for publication: 15 April 2019.

Accepted for publication: 7 April 2020.

This work is licensed under a Creative Commons AttributionNonCommercial 4.0 International License (CC BY-NC 4.0).

CC Copyright: the Author(s), 2020

Licensee PAGEPress, Italy

Health Psychology Research 2020; 8:8234

doi:10.4081/hpr.2020.8234 individual's life such as higher self-esteem, better quality of life and psychological wellbeing. The purpose of this study was to examine the relation between nurses' religiosity, psychological resilience, and psychological wellbeing. In this cross-sectional study, 378 nurses participated. Dada were collected by using Centrality of Religiosity Scale, The Patient Health Questionnaire Two-Item Depression Scale, The Generalized Anxiety Disorder Questionnaire, Connor-Davidson Resilience Scale 25. Percentages, means, and standard deviations were calculated. In addition the parametric t-test and ANOVA were used. Also, logistic regression analyses were used to determine which factors affect the depression and anxiety of nurses. Results indicated differences with a probability of less than or equal to 0.05 were accepted as significant. For statistical analysis, we used the statistical program SPSS 25. According to our results although religious practices can be a protective factor for both depression and anxiety, religious beliefs and experiences can increase the levels of depression and anxiety as well.

\section{Introduction}

The nursing profession is considered to be an emotionally demanding profession often lead to various psychological difficulties and extend level stress. In general, nurses are supposed to be more prone to anxiety and job burnout and often are led to experiencing psychiatric disorders. Researchers attribute this phenomenon to the responsibility that nurses have for patients' health and wellbeing (Fradelos 2014; Papathanasiou, 2017). In research conducted in Hong Kong found that primary care nurses have low levels of anxiety and feel healthy. There is a strong difference between these nurses and their colleagues working in hospitals. The researcher attributes the result to the fact that these nurses do not come in contact with the stress of death in their work (Lee, Hwang, Kim, \& Daly, 2004). In Greece the most important factors of the onset and maintenance of mental disorders were those related to the nature of nursing profession such as daily contact with human pain and end-stage patients, as well as factors related insufficient nursing potential, lack of training and continuing training (Antoniou, Looper, \& Davidson, 2016; Fradelos, 2014).

Religiosity and religion in general, have been associated with positive outcomes in an individual's life such as higher self-esteem, better quality of life and psychological wellbeing. In a study among Iranian nurses, in which religious coping and quality of working life were examined, it was found that positive religious coping was associated with high levels of quality of working life (Bagheri- 
Nesami et al., 2017). In another study conducted among nursing students in Bosnia and Herzegovina was found that higher religiosity can act as a potential resilience factor in the specific population (Dilber et al., 2016). A study conducted in Uganda indicated that religion influences nurses work-lives as well as the coping mechanisms of Ugandian nurses. In addition, the previous study revealed that various religious values seem to affect job performance and various religious activities help them to cope with work-related stress (Bakibinga, Vinje \& Mittelmark, 2013). On the other hand, studies indicate that negative perceptions about God and religion may lead to poor psychological wellbeing and distress (Scandrett \& Mitchell 2009). While in a study conducted among breast cancer patients was found that negative religious coping predicts worse psychological adjustment (Hebert, Zdaniuk, Schulz \& Scheier, 2009).

The purpose of this study was to examine the relation between nurses' religiosity, psychological resilience, and psychological wellbeing. We expected that high levels of religiosity will be associated with resilience and less depression and anxiety.

\section{Materials and Methods}

\section{Study population}

The sample of the study consisted of 378 nurses ( 84 men and 294 women). Data were collected from two public hospitals in Greece. Criteria for inclusion in the study were: 1) ability to write and read the Greek language fluently and 2) working in hospital. The exclusion criterion was nurses without a history of mental illness. Data collection was performed via an interview using a questionnaire developed by the researchers so as to fully serve the purposes of the study. The data collected for each nurse included: socio-demographic characteristics (e.g. gender, age, educational level), and other nurses' characteristics. Completion of the questionnaires lasted approximately $10 \mathrm{~min}$ and took place during the nursing shift. In the present study, there was no control group.

\section{Ethical considerations}

Nurses who met the entry criteria were informed by the researcher for the purposes of the study and participated only after they had given their written consent. All of the nurses participated in the study on a voluntary basis and had their anonymity preserved. All participants were informed of their rights to refuse or to discontinue their participation, according to the ethical standards of the Helsinki Declaration of 1983. The study was approved by the Medical Research Ethics Committee of each hospital.

\section{Assessment of religiosity}

The religiosity of nurses was examined by the evaluation of the Centrality of Religiosity Scale (CRS) which was proposed by Huber in 2003 and assesses the importance or salience of religious meanings in personality. It includes five aspects of religiosity intellectual domain, ideology, private and public practice and finally the domain of religious experience. The scale consists of two subscales: the subscale of religious practices and the subscale of religious beliefs and experiences. All items are answered on a fivepoint Likert scale, ranging from 1 to 5. For the items which measure frequencies the five answers can be: never, rarely, occasionally, often, and very often, ranging from 1 to 5 . The CRS scale has been translated and tested for its validity and reliability in the Greek population (Fradelos et al., 2018).

\section{Assessment of anxiety and depression}

The anxiety and depression of nurses were evaluated by the short questionnaire. In the questionnaire two sections were included: 1) The Patient Health Questionnaire Two-Item Depression Scale (PHQ-2) which has been shown to be a reliable and valid ultra-brief tool for assessing diagnosis of depression, severity, and outcome (Kroenke et al., 2003; Lowe et al., 2005). The frequency of each symptom over the previous two weeks is assessed with response options including "not at all", "several days", "more than half the days", and "nearly every day." These responses are scored $0,1,2$, or 3 , respectively, resulting in a total score that can range from 0 to 6 , with higher scores representing more severe depressive symptoms. PHQ-2 scores of 3 or greater indicate clinically significant depression. 2) The Generalized Anxiety Disorder Questionnaire (GAD-2) is a short version of the tool that is composed of the first two questions of the GAD-7 (Spitzer et al., 2006). Normative values are available (Löwe et al., 2010). The tool is a validated screening severity measure for generalized anxiety disorder as well as a good screening measure for panic, social anxiety, and posttraumatic stress disorders. The scale has been translated and tested for its validity and reliability in the Greek population (Konstantakopoulos et al.,2013).

\section{Assessment of resilience}

The psychological resilience was measured with ConnorDavidson Resilience Scale 25 (CD-RISC-25) (Connor and Davidson 2003, Windle et al., 2011), a self-evaluation instrument with 25 items that are ranked on a Likert scale from 0 to 4 points. The full range of the scale is $0-100$ points, where higher scores indicate higher resilience. The instrument has been proven valid for Greek population by previous studies (Tsagkaropoulou et al., 2018).

\section{Statistical analysis}

Percentages, means, and standard deviations were calculated in order to provide a broader view of the data. Reliability of the instruments was tested with Cronbach's Alpha coefficient was used and found to be for CRS $\alpha=0.946$, RISC25 $\alpha=0.935$, GAD-2 $\alpha=0.798$. All data exhibited normal distributions and thus the parametric t-test and ANOVA were used. Pearson correlation coefficient was used to identify the relationship between the studied variables. Also, logistic regression analyses were used to determine which factors affect the depression and anxiety of nurses. Results indicated differences with a probability of less than or equal to 0.05 were accepted as significant. For statistical analysis, we used the statistical program SPSS 25.

\section{Results}

From the total of the sample, $77.8 \%$ were female. The age ranged from 23 to 61 years old with a mean of $44.01 \pm 7.84$. The working experience ranged from 1 to 37 years, with a mean of $17.17 \pm 9.05$. Finally, regarding their religious preference, most of them were Christians Orthodox (97.1\%) (Table 1).

Additionally, in order to assess depressive symptoms in nurses based on their psychometric values, nurses completed the PHQ-2. Mean depression scores were 2.39 and $\mathrm{SD}=1.5$ on the PHQ-2. A percentage of $22 \%$ of respondents indicated a depressed mood. Moreover, the anxiety severity measured with the GAD-2, where the mean was 2.33 and $\mathrm{SD}=1.65$ while $26 \%$ of nurses suffered from high anxiety. Also, the resilience of nurses was measured with $\mathrm{CD}$ - 
RISC25 with Mean=75.59 and SD=14.37.

Furthermore, statistical significance was found between the resilience scale CD-RISC-25 and both of two subscales of religiosity scale CRS; Religious Practices $(r=.133, p=.005)$ and Religious Beliefs and Experiences $(r=.121, p=.014)$. Also, nurses' Depression (PHQ-2) was correlated with Religious Beliefs and Experiences $(r=.113, p=.028)$ while the Anxiety was correlated statistically significant negative with the the Resilience of nurses $(r=-.131, p=.011)$.

Also, statistically significant differences were found between gender and religiosity. Women are more religious both in practices $(t(376)=.245, p=.00001)$ and in religious beliefs and experiences $(t(376)=.024, p=.00001)$. To describe these interactions in detail, we carried out the Independent Samples Test. Specifically, women use more religious practice $(M=3.08, S D=0.992)$ than men $(M=2.29$, $S D=1.054)$, and more religious beliefs and experiences $(M=3.0179$, $S D=0.94367)$ than men $(M=2.4557, S D=1.01653)$. Likewise, there is a statistically significant difference between marital status and religious beliefs and experiences $(F(4,373), p=0.004)$. To describe these interactions in detail, we carried out one-way ANOVA for each scale. Specifically, married nurses use more religious beliefs and experiences $(M=2.946, S D=0.95233$ than single nurses $(M=2.6758, S D=1.02992)$.

Regression analysis indicates that religious practice and religious beliefs and experiences can predict e nurses' depression as it is shown in Table 2. Especially, the coefficient $R^{2}=0.037$, that is, $37 \%$ of the dispersion of the performance of depression nurses can be interpreted by the influence of independent variables. The review of regression factors has shown that religious practice contributes negatively to anticipating the performance of depression ( $\beta=0-451, t=-2847, p=0.005)$. While beliefs and experiences contribute positively to anticipating the performance of nurses' depression $(\beta=0.580, t=3.502, p=0.001)$.

On the other hand, the result of regression shows that religious practice and religious beliefs and experiences can prognosticate nurses' anxiety as it is shown in Table 3. Especially, the coefficient $\mathrm{R}^{2}=0.031$, that is, $31 \%$ of the dispersion of the performance of nurses' anxiety can be interpreted by the influence of independent variables. The review of regression factors has shown that religious practice contributes negatively to anticipating the performance of anxiety $(\beta=-421, t=-2449, p=0.015)$. While beliefs and experiences contribute positively to anticipating the performance of nurses' anxiety $(\beta=0.526, \mathrm{t}=2.870, \mathrm{p}=0.004)$.

Finally, regression analysis shows that resilience doesn't affect either religious practices or religious beliefs and experiences.

\section{Discussion}

The aim of this study was to examine if nurses' religious beliefs and practices can enhance nurses' resilience and if can be a protective factor for depression and anxiety. These richly descriptive data of our study indicating that, although religious practices can be a protective factor for both depression and anxiety, religious beliefs and experiences can increase the levels of depression and anxiety as well.

According to our results, women nurses reported higher scores of religiosity both in religious practices and religious beliefs and experiences. These findings are consistent with the previously published literature and reinforce findings arguing that women are more religious than men (Carapina, 2015). This has been a predominant idea within the social scientific and psychological research of religion (Beit-Hallahmi \& Argyle, 1975; Paloutzian, 1996). Those gender differences in levels of religious beliefs and involvement as well as in the total religiosity been attributed to the fact that women can have of greater opportunity for attendance to religious activities and practices or some suggest that differences are associated with differences in personality and socialization (Beit-Hallahmi \& Argyle, 1997). The result should be considered through the lens of the Orthodox confessional belonging of the vast majority of respondents, who are the bearers of the Christian Orthodox culture. Contemporary researchers in ethnic processes (Danylova, 2016; Danylova, 2017) determine the specific

Table 1. Descriptive statistics of sample characteristics $(n=378)$.

\begin{tabular}{llcc} 
Characteristics & & N & $\%$ \\
Sex & Male & 84 & 22.2 \\
Marital Status & Female & 294 & 77.8 \\
& Single & 93 & 24.6 \\
& Married & 250 & 66.1 \\
& Divorced & 29 & 7.7 \\
& Widowed & 6 & 1.6 \\
\hline Educational Status & Primary school & 3 & 0.8 \\
& Junior High school & 10 & 2.6 \\
& High school & 145 & 38.4 \\
& University degree & 167 & 44.2 \\
Profession & Postgraduate degree & 53 & 14 \\
& Nurse & 306 & 81 \\
\hline Religion & Nurse assistant & 71 & 18.8 \\
& Christian orthodox & 367 & 97.1 \\
& Christian catholic & 2 & 0.5 \\
& Muslim & 2 & 0.5 \\
Years in the profession & Other & 7 & 1.9 \\
& Mean (SD) & $17.17(9.05)$ & \\
& Min - Max & $1-37$ & \\
\hline Age & Mean (SD) & $44.01(7.84)$ & \\
\hline
\end{tabular}

SD, standard deviation.

Table 2. Effect of religious practices, religious beliefs, and experiences in nurses' depression. Adjusted for age, sex, marital status and educational status.

\begin{tabular}{lccccc} 
Model & B & SE & Beta & t & Sig \\
(Constant) & 0.932 & 0.697 & & 1,337 & 0.182 \\
Religious practices & -0.451 & 0.158 & -0.317 & $-2,847$ & 0.005 \\
\hline Religious beliefs and experiences & 0.580 & 0.166 & 0.380 & 3,502 & 0.001 \\
\hline
\end{tabular}

Dependent Variable: depression.

Table 3. Effect of religious practices, religious beliefs, and experiences in nurses' anxiety. Adjusted for age, sex, marital status and educational status.

\begin{tabular}{lccccc} 
Model & B & SE & Beta & t & Sig \\
(Constant) & 1.246 & 0.772 & & 1.614 & 0.107 \\
Religious practices & -0.429 & 0.175 & -0.273 & -2.449 & 0.015 \\
\hline Religious beliefs and experiences & 0.526 & 0.183 & 0.313 & 2.870 & 0.004 \\
\hline
\end{tabular}

Dependent Variable: anxiety. 
behavioral activity of the representatives of different cultures. Thus, it is possible to speak about the existence of the certain stable Orthodox cultural constructs, patterns of the respondents' valuesemantic sphere, as well as a certain determination effect of these constructs, patterns of behavioral activity of the nurses. The results of statistical analysis allow concluding that religiosity determines the daily and professional activity of nurses in modern conditions.

According to our results, $22 \%$ of respondents reported depressed mood, 26\% suffered from troubling levels of anxiety. These results are consistent with other studies that are reporting similar rates of depression and anxiety (Tsaras et al., 2018; Schmidt, Dantas, \& Marziale, 2011; Papathanasiou et al., 2017). The nursing profession is considered being an emotionally demanding and very stressful occupation. The frequent or constant exposure to stress resulting in high prevalence of depression and anxiety for the specific group of health professionals. In addition, contemporary social environment, social conditions, activities related to social roles, family status, fulfillment of duties according to these roles and status may be seen as essential correlates that affect manifestations of nurses' depression and anxiety.

In our study, nurses reported in resilience scale Mean score 75.59 (14.37) reflecting moderate levels of resilience. In a study conducted in Australia in 2007 (Gillespie, Chaboyer, Wallis, \& Grimbeek, 2007) among Operating theatre, surgical nurses were reported similar score. The reported value of resilience of our study is higher than of other studies. Within the context of a study which conducted by Baek, Lee, Joo, Lee, \& Choi (2010) resilience was studied among a sample of young (average age $=27.4$ ) Korean population of 576 students, nurses, and firefighters. The mean score of resilience was found to be 61.2. Moreover, despite the fact that resilience was found to be significantly correlated to religiosity, this relationship field to be proved within the linear regression analyses. This finding is consisted and reinforcing results from other studies which have been conducted in diverse populations and conclude that religion doesn't enhance psychological resilience (Mizuno et al., 2017)

In general, nurses' religiosity is an essential resource which increases their adaptive potential, allows gaining a "sense of support", defines the purpose and meaning of any effort. The frequency of manifestations of religiosity in daily life and the degree of personal religiosity promote positive effect on their personal resilience. Therefore, the obtained statistical results indicate the linear conditionality/dependence of the level of resilience on the frequency of manifestations of religiosity in daily activity (Kasen, Wickramaratne, Gameroff, \& Weissman, 2011). According to regression analysis, it was found that religious practices contribute greatly to the reduction of depression and anxiety. At the level of daily activity, "religiosity" of personality manifests in the nature of integration into the order of church-liturgical life, in the manner of performing religious practices. It is widely accepted that religion and attendance to religious rituals and performing religious practices offer a sense of coherence and it is a social support resource. Our finding is in partial accordance with other studies indicating that religiosity can improve the mental health of nurses (Cheung, Lee \& Yip, 2017). That's why one of our main findings was that religious beliefs may increase levels of depression and anxiety. Also, a positive linear relationship was found between the level of depression and actualization of religious beliefs. For some, God can be associated with the concepts of sin and punishment. In a recent study conducted by Tong and Teo (2018) was reported that religious concepts and thoughts of God may increase negative emotions and thus, can be associated with the prevalence of depression and anxiety. In addition, in the large scale international cohort study of
Leurent et al. (2013) in which 8318 individuals participated, it was found that participants with strong religious belief had twice the risk for the onset of depression than participants with weak religious beliefs, setting in doubt the generally accepted notion that religious and spiritual life views enhance psychological well-being.

\section{Strengths and limitations of the study}

One of the main strengths of our research is the large sample size and the cross-sectional study design which allows us to have a clear view of the effect of religiosity in psychological variables among nurses. Our study has limitations, as well. It aimed to explore the effect of religiosity in anxiety, depression, and resilience of nurses, precisely in the Orthodox-cultural context (since the vast majority of the respondents identified themselves as Orthodox Christians). However, the results of the study may be extrapolated to the other forms of religious activity (relevant features should be taken into account).

\section{Conclusions}

This study attempted to enlighten the relationship between religiosity and psychological wellbeing of nurses. Our findings were mixed and don't allow us to drown some conclusion if the relationship is positive or not. For sure, religion can provide some comfort and a sense of coherence on nurses mostly through the social support that religious communities can offer. At the same time, the results of our study point out the need for more detailed research on the manifestations of religiosity in the consciousness of the contemporary personality in order to determine the specificity of its' impact on anxiety, depression, and resilience.

\section{References}

Antoniou, A.S., Looper, C.L., \& Davidson, M.J. (2016). Levels of job dissatisfaction and work-related stressors experienced by medical doctors in Greek hospitals. BMC Journal of Compassionate Health Care, 3, 4.

Baek, H.S., Lee, K.U., Joo, E.J., Lee, M.Y., \& Choi, K.S. (2010). Reliability and validity of the korean version of the ConnorDavidson Resilience Scale. Psychiatry Investigation, 7 (2), 109-115.

Bagheri-Nesami, M., Kazemi, A., Goudarzian, A. H., Nasiri, F., \& Davari, J. (2017). Association between religious coping and quality of working life in nurses. Iranian Journal of Psychiatry and Behavioral Sciences, 11(1).

Bakibinga, P., Vinje, H. F., \& Mittelmark, M. (2014). The role of religion in the work lives and coping strategies of Ugandan nurses. Journal of religion and health, 53(5), 1342-1352.

Beit-Hallahmi, B., \& Argyle, M. (1997). The psychology of religious belief, behaviour and experience. London: Routledge.

Carapina, I. (2015). Women are more religious than men; is this true? Journal of Psychology and Clinical Psychiatry, 2 (1), 00056.

Cheung, T., Lee, P.H., \& Yip, P.S.F. (2017). The associations between religion, bereavement and depression among Hong Kong nurses. BMC Research Notes, 10 (1), 242.

Connor, K. M., \& Davidson, J. R. (2003). Development of a new resilience scale: The Connor-Davidson resilience scale (CDRISC). Depression and anxiety, 18(2), 76-82.

Danylova, T.V. (2016). The desire for recognition in the context of Francis Fukuyama's Universal History. Anthropological 
Measurements of Philosophical Research, 10, 69-77.

Danylova, T.V. (2017). Searching for the true self: the way of nondual wisdom. Anthropological Measurements of Philosophical Research, 12, 7-15.

Dilber, R., Babić, D., Vasilj, I., Martinac, M., Babić, R., \& AukstMargetić, B. (2016). Religiosty and mental health in nursing students. Psychiatria Danubina, 28(2), 188-192.

Fradelos, E. C., Kourakos, M., Zyga, S., Tzavella, F., Tsaras, K., Christodoulou, E., ... \& Papathanasiou, I. V. (2018). Measuring Religiosity in Nursing: Reliability, Validity and Psychometric Properties of the Greek Translation of the Centrality of Religiosity Scale-15. American Journal of Nursing, 7(3-1), 2532.

Fradelos, E., Tzitzikos, G., Giannouli, V., Argyrou, P., Vassilopoulou, C., \& Theofilou, P. (2014). Assessment of BurnOut and Quality of Life in Nursing Professionals: The Contribution of Perceived Social Support. Health psychology research, 2(1), 984.

Gillespie, B., Chaboyer, W., Wallis, M., \& Grimbeek, P. (2007). Resilience in the operating room: developing and testing of a resilience model. Journal of Advanced Nursing, 59(4), 427-438.

Hebert, R., Zdaniuk, B., Schulz, R., \& Scheier, M. (2009). Positive and negative religious coping and well-being in women with breast cancer. Journal of Palliative Medicine, 12(6), 537-545.

Kasen, S., Wickramaratne, P., Gameroff, M. \& Weissman, M. (2011). Religiosity and resilience in persons at high risk for major depression. Psychological Medicine, 42(3), 509-519.

Konstantakopoulos, G., Sofianopoulou, E., Touloumi, G., \& Ploubidis, D.(2013). Ultra-short questionnaires for the detection of depression and anxiety. Psychiatriki, 24(4), 288-297.

Kroenke, K., Spitzer, R. L., \& Williams, J. B. (2003). The Patient Health Questionnaire-2: validity of a two-item depression screener. Medical care, 1284-1292.

Lee, H., Hwang, S., Kim, J., Daly, B. (2004). Predictors of life satisfaction of Korean nurses. Journal of Advanced Nursing, 48(6), 632-641.

Leurent, B., Nazareth, I., Bellón-Saameño, J., Geerlings, M.I., Maaroos, H., Saldivia, S., ... \& King, M. (2013). Spiritual and religious beliefs as risk factors for the onset of major depression: an international cohort study. Psychological Medicine, 43(10),
2109-2120.

Löwe, B., Wahl, I., Rose, M., Spitzer, C., Glaesmer, H., Wingenfeld, K., ... \& Brähler, E. (2010). A 4-item measure of depression and anxiety: validation and standardization of the Patient Health Questionnaire-4 (PHQ-4) in the general population. Journal of affective disorders, 122(1-2), 86-95.

Mizuno, Y., Hofer, A., Frajo-Apor, B., Wartelsteiner, F., Kemmler, G., Pardeller, S., ... \& Uchida, H. (2017). Religiosity and psychological resilience in patients with schizophrenia and bipolar disorder: an international cross-sectional study. Acta Psychiatrica Scandinavica, 137(4),316-327.

Paloutzian, R.F. (1996). Invitation to the psychology of religion. (2nd ed). Boston, MA: Allyn and Bacon.

Papathanasiou, I., Tsaras, K., Kleisiaris, C., Fradelos, E., Tsaloglidou, A. \& Damigos, D. (2017). Anxiety and depression in staff of mental units: the role of burnout. Advances in Experimental Medicine and Biology, 987, 185-197.

Scandrett, K.G., \& Mitchell, S.L. (2009). Religiousness, religious coping, and psychological well-being in nursing home residents. Journal of the American Medical Directors Association, 10(8), 581-586.

Schmidt, D., Dantas, R., \& Marziale, M. (2011). Ansiedad y depresión entre profesionales de enfermería que actúan en sectores quirúrgicos. Revista da Escola de Enfermagem da USP, 45(2), 487-493.

Spitzer, R. L., Kroenke, K., Williams, J. B., \& Löwe, B. (2006). A brief measure for assessing generalized anxiety disorder: the GAD-7. Archives of internal medicine, 166(10), 1092-1097.

Tong, E.M.W., Teo, A.Q.H. (2018). The influence of religious concepts on the effects of blame appraisals on negative emotions. Cognitions, 177, 150-164.

Tsaras, K., Papathanasiou, I., Vus, V., Panagiotopoulou, A., Katsou, M., Kelesi, M., \& Fradelos, E. (2018). Predicting factors of depression and anxiety in mental health nurses: a quantitative cross-sectional study. Medical Archives, 72(1), 62.

Tsigkaropoulou, E., Douzenis, A., Tsitas, N., Ferentinos, P., Liappas, I., \& Michopoulos, I. (2018). Greek Version of the ConnorDavidson Resilience Scale: Psychometric Properties in a Sample of 546 Subjects. In vivo, 32(6), 1629-1634. 